\title{
Hydroxyl in the stratosphere and mesosphere - Part 1: Diurnal variability
}

\author{
K. Minschwaner ${ }^{1}$, G. L. Manney ${ }^{1,2}$, S. H. Wang ${ }^{2}$, and R. S. Harwood ${ }^{3}$ \\ ${ }^{1}$ Department of Physics, New Mexico Institute of Mining and Technology, Socorro, USA \\ ${ }^{2}$ Jet Propulsion Laboratory, California Institute of Technology, Pasadena, USA \\ ${ }^{3}$ University of Edinburgh, Edinburgh, UK \\ Received: 9 August 2010 - Published in Atmos. Chem. Phys. Discuss.: 28 September 2010 \\ Revised: 19 January 2011 - Accepted: 20 January 2011 - Published: 2 February 2011
}

\begin{abstract}
Diurnal variations in hydroxyl $(\mathrm{OH})$ in the stratosphere and mesosphere are analyzed using measurements from the Aura Microwave Limb Sounder (MLS). The primary driver for $\mathrm{OH}$ diurnal variations is the ultraviolet actinic flux that initiates the photochemical production of reactive hydrogen species. The magnitude of this flux is governed largely by changes in solar zenith angle (SZA) throughout the day, and $\mathrm{OH}$ diurnal variations are well approximated by an exponential function of the secant of SZA. Measured $\mathrm{OH}$ concentrations are fit to a function of the form $\exp [-\beta \sec (\mathrm{SZA})]$, where the parameter $\beta$ is a function of altitude. We examine the magnitude of $\beta$ and show that it is related to the optical depths of ultraviolet absorption by ozone and molecular oxygen. Values of $\beta$ from SLIMCAT model simulations show the same vertical structure as those from MLS and the average level of agreement between model and measurements is $6 \%$. The vertical profile of $\beta$ from MLS can be represented by a simple analytic formulation involving the ozone and water vapor photodissociation rates. This formulation is used to infer the altitude dependence of the primary production mechanisms for $\mathrm{OH}$ : the reaction of excited-state atomic oxygen with water vapor versus the direct photodissociation of water vapor.
\end{abstract}

\section{Introduction}

Hydroxyl $(\mathrm{OH})$ is a key reactive species for photochemical reactions that regulate ozone throughout most of the stratosphere ( $\sim 20-55 \mathrm{~km}$ altitude) and mesosphere ( $\sim 55-90 \mathrm{~km})$. Catalytic cycles involving $\mathrm{OH}$ dominate the chemical loss of ozone in the upper stratosphere (McElroy and Salawitch, 1989) and in the lower stratosphere (Wennberg et al., 1994). Reactions with $\mathrm{OH}$ and $\mathrm{HO}_{2}$ are also important in conversions between reactive and stable forms of chlorine and nitrogen in the stratosphere (e.g., Dvortsov and Solomon, 2001). The diurnal variation of hydroxyl is tightly linked to the intensity of solar ultraviolet radiation (Wennberg, 2006 and references therein), and therefore to the slant path absorption of radiation through the overlying atmosphere, which varies over the course of the day due to the changing elevation of the sun.

The key production reactions for $\mathrm{OH}$ in the stratosphere and mesosphere are

$$
\begin{aligned}
& \mathrm{H}_{2} \mathrm{O}+\mathrm{O}\left({ }^{1} \mathrm{D}\right) \rightarrow 2 \mathrm{OH} \\
& \mathrm{H}_{2} \mathrm{O}+h v \rightarrow \mathrm{OH}+\mathrm{H}
\end{aligned}
$$

while the loss is determined mainly through

$\mathrm{OH}+\mathrm{HO}_{2} \rightarrow \mathrm{H}_{2} \mathrm{O}+\mathrm{O}_{2}$

It is convenient to define the odd hydrogen family, $\mathrm{HO}_{\mathrm{x}}=\mathrm{OH}+\mathrm{HO}_{2}+\mathrm{H}$, so that the production of $\mathrm{HO}_{\mathrm{x}}$ from Reactions (R1) and (R2) is equivalent to the production of $\mathrm{OH}$, provided that the ratios $\mathrm{OH} / \mathrm{HO}_{2}$ and $\mathrm{OH} / \mathrm{H}$ remain approximately constant for the timescales of interest (e.g., Brasseur and Solomon, 2005). If a photochemical steady state is assumed for the production and loss of $\mathrm{HO}_{\mathrm{x}}$ from Reactions (R1-R3), and if equilibrium is assumed among the $\mathrm{HO}_{\mathrm{x}}$ species $\mathrm{OH}, \mathrm{HO}_{2}$, and $\mathrm{H}$, then the concentration of hydroxyl is determined by the following proportionality (Canty and Minschwaner, 2002)

\section{Correspondence to: K. Minschwaner}

(krm@nmt.edu) 
$[\mathrm{OH}] \propto \sqrt{k_{1}\left[\mathrm{H}_{2} \mathrm{O}\right]\left[\mathrm{O}\left({ }^{1} \mathrm{D}\right)\right]+J_{\mathrm{H}_{2} \mathrm{O}}\left[\mathrm{H}_{2} \mathrm{O}\right]}$

where $k_{1}$ is the rate constant for Reaction (R1), $J_{\mathrm{H}_{2} \mathrm{O}}$ is the photodissociation rate for $\mathrm{H}_{2} \mathrm{O}$ (Reaction $\mathrm{R} 2$ ), and square brackets indicate concentrations of chemical species. The square root dependence arises from a quadratic loss term for $\mathrm{HO}_{\mathrm{x}}$ by Reaction (R3). The concentration of $\mathrm{O}\left({ }^{1} \mathrm{D}\right)$ is directly proportional to the photodissociation rate for ozone in the Hartley band, $J_{\mathrm{O}_{3}}$.

$\left[\mathrm{O}\left({ }^{1} \mathrm{D}\right)\right] \propto J_{\mathrm{O}_{3}}\left[\mathrm{O}_{3}\right]$

We thus have two photodissociation rates of interest - ozone and water vapor. A general expression for the photodissociation rate contains an exponential function of the secant of the solar zenith angle (SZA),

$\left.J=\int \epsilon_{\lambda} I_{\lambda} \sigma_{\lambda} \exp \left[-\tau_{\lambda} \sec (\mathrm{SZA})\right] d \lambda\right]$

where $\sec (\mathrm{SZA})=1 / \cos (\mathrm{SZA})$, and $\varepsilon, I, \sigma$, and $\tau$ are the quantum yields, solar irradiances, absorption cross sections, and vertical optical depths which are all generally functions of wavelength $\lambda$. Note that Eq. (3) is valid only for the direct solar radiation and neglects diffuse irradiance from cloud, aerosol, or Rayleigh scattering. This diffuse component is generally small above $30 \mathrm{~km}$ and for wavelengths shorter than $320 \mathrm{~nm}$ (Meier and Anderson, 1982), conditions that are relevant to the production of $\mathrm{HO}_{\mathrm{x}}$ in the mid-to-upper stratosphere and mesosphere. Photolysis calculations indicate a typical impact of $5-15 \%$ due to scattering on $\mathrm{O}\left({ }^{1} \mathrm{D}\right)$ production near $30 \mathrm{~km}$, but this decreases rapidly with increasing altitude and is less than $1 \%$ above $50 \mathrm{~km}$. Based on these considerations and on the combination of Eqs. (1-3), the dependence of $\mathrm{OH}$ on SZA should assume the form of an exponential function of $\sec (\mathrm{SZA})$.

In this paper we characterize the $\mathrm{OH}$ diurnal variation using data from the Microwave Limb Sounder (MLS) on the Aura satellite (Waters et al., 2006). The daytime MLS $\mathrm{OH}$ measurements have been analyzed previously in comparisons with balloon and ground-based observations (e.g. Canty et al., 2006; Wang et al., 2008), but the $\mathrm{OH}$ diurnal variations implied by the MLS measurements have not been examined in any detail. The issue of diurnal variability is also relevant to recent measurements of mesospheric $\mathrm{OH}$ from satellite instruments using ultraviolet techniques (Englert et al., 2008; Gattinger et al., 2006).

Our objectives are to characterize $\mathrm{OH}$ diurnal variations as seen in the extensive $\mathrm{OH}$ dataset from MLS that spans a wide range of latitudes and time, and to use the observations to test our understanding of the radiative processes that drive the photochemistry of $\mathrm{OH}$. We develop a simple parameterization that is capable of describing the $\mathrm{OH}$ diurnal variation as a function of solar zenith angle. Examination of the altitude dependence in this parameterization permits the interpretation of the observations as they relate to the photodissociation rates for ozone and water vapor.

\section{OH diurnal variation}

We use MLS v2.2 OH mixing ratios from Northern Hemisphere summer months (July-September), when the smallest values of SZA $\left(\sim 18^{\circ}\right)$ are accessed due to the Aura orbital characteristics. The pressure range for scientifically useful daytime $\mathrm{OH}$ data is $32 \mathrm{hPa}$ to $0.0032 \mathrm{hPa}$, but at the two lowermost pressure levels, i.e. 32 and $21 \mathrm{hPa}$, a day-night correction is required and the precision is not as good as it is at higher altitudes (Pickett et al., 2008). This analysis is restricted to pressures between $10 \mathrm{hPa}(\sim 30 \mathrm{~km})$ and $0.02 \mathrm{hPa}$ $(\sim 76 \mathrm{~km})$, where systematic errors in $\mathrm{v} 2.2 \mathrm{OH}$ densities are $8 \%$ or less. The upper pressure limit at $0.02 \mathrm{hPa}$ was chosen to avoid complications from the increasingly long lifetime of $\mathrm{HO}_{\mathrm{x}}$ species in the upper mesosphere (Allen et al., 1984), which are generally not in photochemical steady state.

Figure 1 shows two vertical profiles of $\mathrm{OH}$ obtained from averaging July-September 2006 MLS measurements. One $\mathrm{OH}$ profile is an average for all measurements obtained within a SZA range $20^{\circ}-25^{\circ}$, while the other profile is an average over the SZA range $65^{\circ}-70^{\circ}$. Each vertical profile was retrieved using a standard optimal estimation method employing a priori profiles as described by Pickett et al. (2008). As the contribution of the a priori profile to the retrieved profile is very small (less than one percent during the daytime and over the pressure range of interest), the averages shown here contain a negligibly small influence from the a priori.

Both vertical profiles in Fig. 1 show an $\mathrm{OH}$ maximum in the stratosphere near $2 \mathrm{hPa}(\sim 43 \mathrm{~km})$, a minimum in the lower mesosphere at $0.15 \mathrm{hPa}(\sim 62 \mathrm{~km})$, and a secondary maximum in the mesosphere near $0.03 \mathrm{hPa}(\sim 73 \mathrm{~km})$. The stratospheric maximum arises from a peak in $\mathrm{HO}_{\mathrm{x}}$ production near $43 \mathrm{~km}$ from Reaction (R1), while the mesospheric maximum is driven primarily by production from Reaction (R2). As expected on the basis of Eqs. (1-3), the overall $\mathrm{OH}$ concentration is largest when the SZA is smallest.

It should be noted that the $\mathrm{OH}$ data shown in Fig. 1 are mean vertical profiles constructed from $\sim 2000$ individual profiles within each SZA range, and the individual profiles may be spread over a large range in latitude, longitude, and local time. For example, the latitude and local time ranges for the $20^{\circ}-25^{\circ}$ profile are $5-45^{\circ} \mathrm{N}$, and 13:00-14:00, respectively. The corresponding ranges for the $65^{\circ}-70^{\circ}$ profile are much larger, $65^{\circ} \mathrm{S}-80^{\circ} \mathrm{N}$ in latitude and 06:00-15:00 in local time.

As discussed above, SZA is expected to be the dominant influence in controlling $\mathrm{OH}$ concentrations, although from Eqs. (1) and (2) there may also be important influences from spatial or temporal variations in $\mathrm{H}_{2} \mathrm{O}$ and $\mathrm{O}_{3}$ concentrations. In Fig. 1 and throughout the remainder of this analysis, we filter the $\mathrm{OH}$ data at each pressure level by including only 


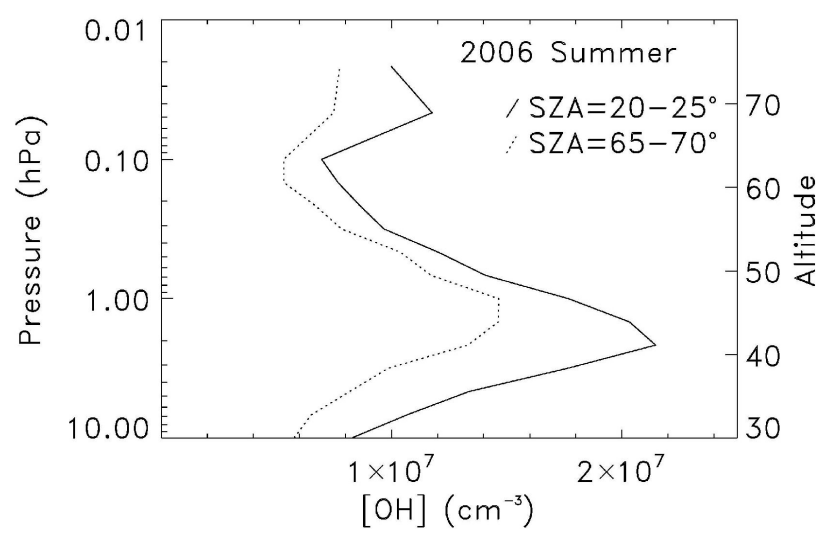

Fig. 1. Mean $\mathrm{OH}$ concentrations measured by MLS during the period July-September 2006, obtained within SZA range of $20-25^{\circ}$ (solid) and $65-70^{\circ}$ (dotted curve), plotted as a function of pressure (left axis) and approximate altitude(right axis).

those data for which the simultaneous MLS measurements of $\mathrm{H}_{2} \mathrm{O}$ and $\mathrm{O}_{3}$ were within $\pm 20 \%$ of the mean value at that pressure level. In this way, filtering by $\mathrm{H}_{2} \mathrm{O}$ and $\mathrm{O}_{3}$ helps to isolate $\mathrm{OH}$ variations due to changing SZA. Assuming the validity of the square-root dependence (Eq. 1), the $\pm 20 \%$ filter threshold corresponds to a maximum $\pm 10 \% \mathrm{OH}$ variation that may not be related to SZA effects.

Hydroxyl data for 2006 at the $2.15 \mathrm{hPa}$ stratospheric maximum is shown in Fig. 2 as a function of solar zenith angle. There are many more data points for the afternoon than for the morning, which is related to the nature of the Aura satellite orbit and to the $\mathrm{H}_{2} \mathrm{O}$ and $\mathrm{O}_{3}$ filtering processes (morning data are primarily from the $\mathrm{NH}$ high latitudes where $\mathrm{H}_{2} \mathrm{O}$ and $\mathrm{O}_{3}$ have a higher variability). We find that the morning averages are similar to afternoon averages at the same SZA (i.e., a small diurnal asymmetry) at most of the levels examined here, with typical morning-afternoon differences of $2-3 \%$ throughout most of the stratosphere. A maximum asymmetry of $6 \%$, with afternoon larger than morning, occurs near $0.02 \mathrm{hPa}$. Ground-based $\mathrm{OH}$ column measurements also generally show larger column amounts in the afternoon compared with the morning. Mills et al. (2003) found a $6 \%$ asymmetry at $45^{\circ} \mathrm{SZA}$ (afternoon larger than morning) from $\mathrm{OH}$ column measurements at the Table Mountain Facility, which Li et al. (2005) showed was due to a $\sim 30$ min phase lag about local noon arising from the finite lifetime of $\mathrm{HO}_{\mathrm{x}}$ in the upper stratosphere and mesosphere. No seasonal differences were found in the diurnal asymmetry (Li et al., 2005). On the other hand, Burnett et al. (1989) obtained a similar mean $\mathrm{OH}$ column asymmetry favoring afternoon (7\%) from Fritz Peak Observatory, but they also found large seasonal variations $(\sim 27 \%)$ in the amplitude of the diurnal asymmetry. During NH summer, the asymmetry favors afternoon by $3-5 \%$.



Fig. 2. Hydroxyl concentrations measured by MLS (points) at the $2.15 \mathrm{hPa}$ pressure level during July-September 2006, as a function of solar zenith angle. Morning values are shown to the left of the $0^{\circ}$ line; afternoon values are to the right. Blue diamonds (red x's) indicate mean values within $5^{\circ} \mathrm{SZA}$ bins for the morning (afternoon), and the blue (red) curve shows the exponential function fit for morning (afternoon) as discussed in the text.

Figure 2 also displays mean values within $5^{\circ}$ SZA bins, along with a two-parameter fit using the equation

$[\mathrm{OH}]=[\mathrm{OH}]_{\mathrm{o}} \exp [-\beta \sec (\mathrm{SZA})]$

The afternoon means in Fig. 2 are based on an average of about 8000 data points; the standard deviation for each mean is on the order of $5 \times 10^{6} \mathrm{~cm}^{-3}$, which is about $25 \%$ of the mean and is consistent with the precision of individual $\mathrm{OH}$ measurements $(\sim 10-15 \%$ at this level) plus the unfiltered geophysical variability due to $\mathrm{H}_{2} \mathrm{O}$ and $\mathrm{O}_{3}(\sim 10 \%)$. The fit parameters for Fig. 2 are $[\mathrm{OH}]_{\mathrm{o}}=2.96 \times 10^{7} \mathrm{~cm}^{-3}$ and $\beta=0.30$. Comparison of Eqs. (3) and (4) suggests that $\beta$ is related to the optical depth of the atmosphere at wavelengths relevant for photolysis. In the following section we explore the behavior of $\beta$ in more detail.

\section{OH solar zenith angle dependence: the $\beta$ parameter}

The analysis discussed above was carried out at all levels between $10 \mathrm{hPa}$ and $0.02 \mathrm{hPa}$, where the observed mean $\mathrm{OH}-$ SZA relationship was fit using Eq. (4) within $5^{\circ}$ SZA bins between $15^{\circ}$ and $75^{\circ}$ (extension to larger SZA complicates the analysis because an adequate treatment of the radiative transfer would require the inclusion of full spherical geometry). Figure 3 shows results for four pressure levels: near the bottom of the MLS OH profile at $6.81 \mathrm{hPa}$, the stratospheric maximum at $2.15 \mathrm{hPa}$, the lower mesospheric minimum at $0.146 \mathrm{hPa}$, and the mesospheric maximum at $0.046 \mathrm{hPa}$. At each level, there are differences in the overall $\mathrm{OH}$ amount as seen in the vertical profiles of Fig. 1. In addition, $\mathrm{OH}$ 


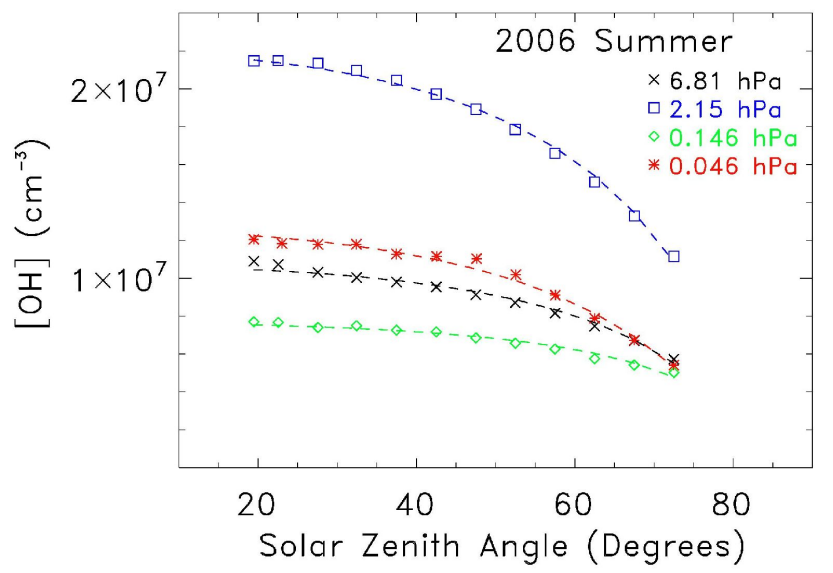

Fig. 3. Hydroxyl concentrations at $6.81 \mathrm{hPa}$ (black x's), $2.15 \mathrm{hPa}$ (blue squares), $0.146 \mathrm{hPa}$ (green diamonds), and $0.046 \mathrm{hPa}$ (red *s) obtained from full-day (morning + afternoon) averages within $5^{\circ}$ solar zenith angle bins. Corresponding dashed curves show exponential function fits as described in the text.

at each level displays a different dependence on SZA as reflected in the steepness of the fits $(\beta$ values are $0.28,0.30$, 0.20 , and 0.37 at $6.81,2.15,0.146$, and $0.046 \mathrm{hPa}$, respectively). Values of $[\mathrm{OH}]_{\mathrm{o}}$ were also obtained from the fits at each pressure level. The altitude dependence of $[\mathrm{OH}]_{\mathrm{o}}$ closely follows the vertical profile of $\mathrm{OH}$ at the smallest SZA $\left([\mathrm{OH}]_{\mathrm{o}}=1.4,3.0,0.9\right.$, and $1.8 \times 10^{7} \mathrm{~cm}^{-3}$ at $6.81,2.15$, 0.146 , and $0.046 \mathrm{hPa}$, respectively; compare with the solid profile in Fig. 1). It should be noted, however, that these values in fact correspond to $\mathrm{OH}$ concentrations extrapolated to zero optical depth, which are never fully realized in the atmosphere. From Fig. 3 we find the goodness of fit is poorer at $0.046 \mathrm{hPa}$ than at other levels, and in general the fits become progressively worse above the stratopause due to higher measurement noise and possible influences from the increasingly longer lifetime of $\mathrm{HO}_{\mathrm{x}}$ species. Nevertheless, Fig. 3 demonstrates that the simple two-parameter fit of Eq. (4) can capture the observed diurnal variability of $\mathrm{OH}$ to within $\pm 5 \%$, provided that $\mathrm{H}_{2} \mathrm{O}$ and $\mathrm{O}_{3}$ are held relatively fixed and that SZA is restricted to values less than $75^{\circ}$.

Figure 4 displays vertical profiles of $\beta$ obtained from MLS data for the NH summers of 2004 through 2008. The profiles show remarkable consistency from year to year between 10 and $0.1 \mathrm{hPa}$. Some of the year-to-year differences above $0.1 \mathrm{hPa}$ are likely due to the increasing level of noise but may also be influenced by real temporal differences in solar irradiances or geophysical variability. The shape of the $\beta$ profile contains two local maxima similar to the $\mathrm{OH}$ concentration profile shown in Fig. 1, although the maxima do not occur at precisely the same pressure levels. Table 1 lists the 5-year average values of $\beta$ and $[\mathrm{OH}]_{\mathrm{o}}$ at each pressure level.

Also shown in Fig. 4 is the vertical profile of $\beta$ derived from $\mathrm{OH}$ values simulated using the SLIMCAT 3-D chemical
Table 1. Mean values of the $\mathrm{OH}-\mathrm{SZA}$ fit parameters $\beta$ and $[\mathrm{OH}]_{\mathrm{o}}$ from MLS measurements during the NH summers of 2004-2008.

\begin{tabular}{lcc}
\hline & & $\begin{array}{c}{[\mathrm{OH}]_{\mathrm{o}} \times 10^{7}} \\
\left(\mathrm{~cm}^{-3}\right)\end{array}$ \\
\hline 10.00 & 0.226 & 1.05 \\
6.81 & 0.302 & 1.50 \\
4.64 & 0.289 & 1.81 \\
3.16 & 0.341 & 2.48 \\
2.15 & 0.303 & 2.97 \\
1.47 & 0.194 & 2.45 \\
1.00 & 0.134 & 2.10 \\
0.681 & 0.105 & 1.57 \\
0.464 & 0.095 & 1.34 \\
0.316 & 0.131 & 1.12 \\
0.215 & 0.172 & 1.07 \\
0.147 & 0.196 & 0.94 \\
0.100 & 0.198 & 0.93 \\
0.0464 & 0.310 & 1.79 \\
0.0215 & 0.257 & 1.37 \\
\hline
\end{tabular}

transport model (Chipperfield, 1999, 2006). This simulation used a $2.8 \times 2.8$ horizontal resolution, with 50 vertical levels from the surface to about $60 \mathrm{~km}$ altitude, with $\mathrm{OH}$ fields interpolated to the MLS measurement spatial sampling grid at the nearest available model time step (always within $15 \mathrm{~min}$ ). Derivation of the SLIMCAT OH diurnal variation was carried out using the same $\mathrm{H}_{2} \mathrm{O}$ and $\mathrm{O}_{3}$ screening method described previously for the MLS data.

The overall shape of the SLIMCAT $\beta$ profile agrees with MLS, and the mean difference between the two profiles is $6 \%$. In the middle and upper stratosphere, there are large gradients in $\beta$ which are related to the vertical distribution of ozone. Here, maximum differences between SLIMCAT and MLS can approach $30 \%$. In the mesosphere, the SLIMCAT simulations are not suitable for a detailed comparison because of the proximity to the model top and uncertainties in the driving winds in that region. In the lower stratosphere, the SLIMCAT value of $\beta$ increases substantially and is in excellent agreement with the value obtained from a fit to the $\mathrm{OH}$ data of Hanisco et al. (2001) as shown in Fig. 4. For this data point, a mean pressure of $65 \mathrm{hPa}$ was adopted for the ER-2 aircraft measurements and the OH-SZA relationship presented by Hanisco et al was fit to an accuracy of $\pm 10 \%$ within the SZA range $15^{\circ}-75^{\circ}$ using Eq. (4) and a $\beta$ value of 0.59. A similar result is obtained from a fit to $\mathrm{OH}$ measurements analyzed by Salawitch et al. (1994).

\section{Implications for photodissociation}

The agreement between the SLIMCAT modeled and MLS observed $\mathrm{OH} \beta$ parameter indicates that the model can 


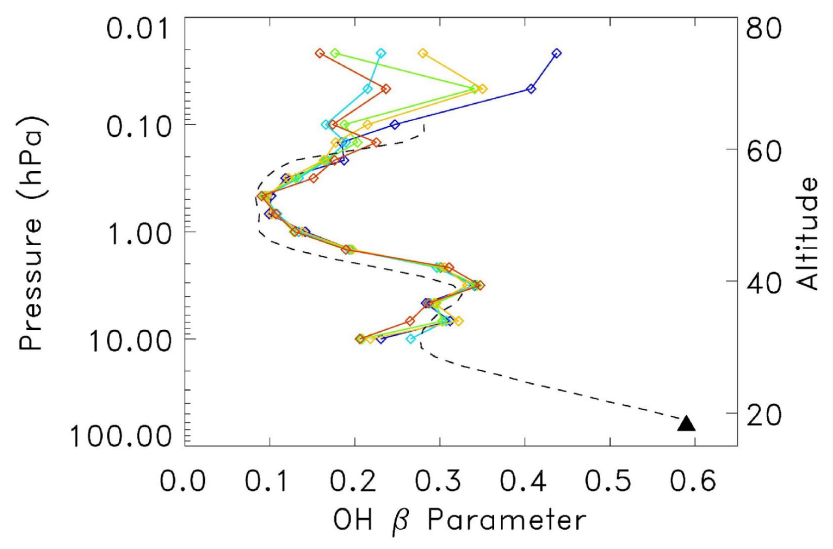

Fig. 4. Vertical profiles of the OH-SZA fit parameter $\beta$ from MLS measurements during the NH summer of 2004 (blue), 2005 (cyan), 2006 (green), 2007 (orange), and 2008 (red). Dashed curve shows the corresponding $\beta$ from simulations of the SLIMCAT model for 2005. Solid triangle indicates $\beta$ value derived from a fit to the aircraft $\mathrm{OH}$ measurements by Hanisco et al. (2001).

realistically simulate the radiative transfer processes and photochemistry involved in the production of $\mathrm{HO}_{\mathrm{x}}$. However, certain aspects of the $\mathrm{OH}$ diurnal behavior raise questions that deserve closer scrutiny. The physical processes that determine $\beta$ at a given pressure level are not particularly clear, nor is the reason that $\beta$ varies between 0.1 and 0.3 in the stratosphere and mesosphere. If the SZA dependence is indeed governed by the slant path absorption of the overlying atmosphere, we might expect that $\beta$ should monotonically increase with increasing pressure (decreasing altitude), rather than displaying two local maxima.

For the highly simplified case where $\varepsilon=1$, and $I, \sigma$ and $\tau$ are independent of $\lambda$, then

$$
J=J_{\infty} \exp [-\tau \sec (\mathrm{SZA})]
$$

where $J_{\infty}$ is the photodissociation rate at the top of the atmosphere. In this case, the $\mathrm{OH} \beta$ parameter is directly related to the optical depth for photodissociation,

$\beta=0.5 \tau$

where the factor of 0.5 arises from the square-root dependence of $\mathrm{OH}$ on $J$ (Eq. 1). Now the optical depth is generally a monotonic function of altitude, $z$, since it is calculated in the general case by

$$
\tau(z)=\int_{z}^{\infty} \sigma n(z) d z
$$

where $n(z)$ is the number density of absorbers. Thus $\tau$ (and $\beta$ ) must increase monotonically with decreasing altitude (or at least, remain constant), independent of $n(z)$ and in opposition to the behavior shown in Fig. 4.
The reasons for the complex altitude dependence of the $\mathrm{OH} \beta$ are threefold. First, the $\beta$ profile in the mesosphere is due primarily to $\mathrm{HO}_{\mathrm{x}}$ production from water vapor photodissociation, while the profile in the stratosphere results from $\mathrm{HO}_{\mathrm{x}}$ production initiated by ozone photodissociation. Second, the $\beta$ profile for water photodissociation contains a maximum near $70 \mathrm{~km}(0.05 \mathrm{hPa})$ around a transition from the Lyman $\alpha$ to the $\mathrm{O}_{2}$ Schumann-Runge (S-R) spectral regions. Third, the $\beta$ profile for ozone photodissociation has a local maximum near $40 \mathrm{~km}(\sim 3-4 \mathrm{hPa})$ that is related to the shape of the Hartley band ozone cross section, and to the fact that the primary source of atmospheric opacity in this spectral region is ozone itself.

Figure 5 shows the average profile of $\mathrm{OH} \beta$ from MLS NH summer measurements (a mean of the five profiles shown in Fig. 4), along with two calculated profiles of $\beta_{J}$ : one profile is derived from $J_{\mathrm{H}_{2} \mathrm{O}}$ alone, and the other is based solely on $J_{\mathrm{O}_{3}}$. In these calculations, $J$-values were determined using a radiative transfer model (Minschwaner et al., 1993) and a midlatitude summer reference atmosphere (Anderson et al., 1986). The solar zenith angle dependencies of $\sqrt{J}$ (cf. Eq. 1) were then fit to functions of $\exp \left[-\beta_{J} \sec (\mathrm{SZA})\right]$. As seen in Fig. 5, each $\beta_{J}$ profile contains a local maximum that appears to match up with the $\mathrm{OH} \beta$ profile. This indicates that the two local maxima in the $\mathrm{OH} \beta$ profile are in fact related to the individual $\beta_{J}$ maxima for $J_{\mathrm{H}_{2} \mathrm{O}}$ in the mesosphere and $J_{\mathrm{O}_{3}}$ in the stratosphere. We now examine in more detail why the individual $\beta_{J}$ are peaked about these maximum values in the mesosphere and stratosphere.

Figure 6 shows two calculations for water vapor photolysis: one considering solely the Lyman $\alpha$ wavelengths $(\sim 121 \mathrm{~nm})$ (Lewis et al., 1983), and one that includes both Lyman $\alpha$ and S-R band photolysis (175-200 nm) (Siskind et al., 1994). In both cases the atmospheric opacity is due primarily to molecular oxygen, but the mean $\mathrm{O}_{2}$ optical depth is larger for Lyman $\alpha$ than for S-R band wavelengths at the same altitude. Similarly, the mean $\mathrm{H}_{2} \mathrm{O}$ cross section is larger at Lyman $\alpha$ wavelengths. The net effect is that the photolysis of $\mathrm{H}_{2} \mathrm{O}$ is dominated by Lyman $\alpha$ at high altitudes (smaller $\tau$ ) and by S-R band wavelengths at lower altitudes (larger $\tau)$ (Nicolet, 1984). This shift in dominance between the two spectral regions (Lyman $\alpha$ above $70 \mathrm{~km}, \mathrm{~S}-\mathrm{R}$ band below $70 \mathrm{~km}$ ) leads to an inflection in the $J_{\mathrm{H}_{2} \mathrm{O}}$ profiles and a subsequent transition to a smaller mean optical depth (and value of $\beta_{J}$ ). In fact this transition is driven by the changes in optical depths of the atmosphere with altitude.

For ozone, the situation would appear simpler since there is just one spectral region of interest; however, the fact that ozone itself is the principal absorber adds complexity to Eq. (3). In this case we have competing effects from two terms in the wavelength integral of Eq. (3): the cross section term $\sigma$ and the transmission term $\exp [-\tau \sec (\mathrm{SZA})]$. Considering an idealized case where the cross section is represented by a triangular function in wavelength, it is easily shown that the $J$-value contains a subtle inflection at the level 


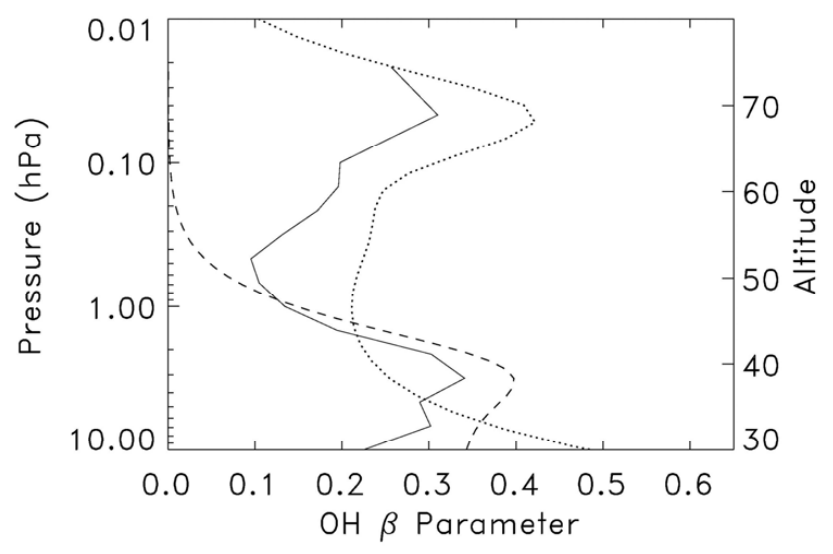

Fig. 5. Mean $\beta$ from 2004-2008 MLS OH NH summer measurements (solid), along with derived values of $\beta$ from ozone photodissociation (dashed) and water vapor dissociation (dotted), assuming a square-root dependence on $\mathrm{HO}_{\mathrm{x}}$ production as described in the text.

where the mean optical depth is unity, i.e., $\bar{\tau}(z)=\bar{\sigma} N(z) \simeq 1$, where $N(z)$ is the vertical column abundance of absorbing molecules. Above this level, photolysis is dominated by absorption at larger values of $\sigma$ (near the peak of the triangular function), whereas below this level, photolysis occurs at smaller values of $\sigma$ (in the wings of the triangle). Correspondingly, there is a shallow maximum in the gradient of the SZA dependence at this level as the photodissociation transitions from larger to smaller values of $\sigma$. For the results shown in Fig. 5, the maximum in $\beta_{J}$ for ozone occurs near $3 \mathrm{hPa}$ where the input $N(z)$ is $3.6 \times 10^{17} \mathrm{~cm}^{-2}$ and the mean ozone cross section is $3.1 \times 10^{-18} \mathrm{~cm}^{2}$, giving a mean optical depth of 1.1 which is in reasonable agreement with the above discussion. Furthermore, the value $\beta_{J}=0.4$ at this maximum (Fig. 5) would imply a mean optical depth of 0.8 (Eq. 6), which is also close to unity and in agreement with this approximate description.

Figure 7 shows a comparison between the mean $\mathrm{OH} \beta$ from MLS and a simulated profile of $\beta$ based on a linear combination of the calculated $J_{\mathrm{H}_{2} \mathrm{O}}$ and $J_{\mathrm{O}_{3}}$, raised to the power of 0.45 . The fact that a reduced exponent from 0.5 to 0.45 produces a better fit to the observed $\beta$ profile is most likely related to deviations from the exact square root dependence in Eq. (1) that arise from neglecting small contributions from (i) linear $\mathrm{HO}_{\mathrm{x}}$ loss terms, and (ii) $\mathrm{HO}_{\mathrm{x}}$ production mechanisms other than $J_{\mathrm{H}_{2} \mathrm{O}}$ and $J_{\mathrm{O}_{3}}$ (i.e., production mechanisms that are not photolysis driven and therefore tend to flatten the $\mathrm{OH}$ diurnal variation).

The coefficients to the linear combination shown in Fig. 7 can be used to derive the relative contribution of $J_{\mathrm{H}_{2} \mathrm{O}}$ and $J_{\mathrm{O}_{3}}$ to the total production of odd hydrogen, $P_{\mathrm{HO}_{\mathrm{x}}}$, throughout the stratosphere and mesosphere $P_{\mathrm{HO}_{\mathrm{x}}} \propto F_{\mathrm{H}_{2} \mathrm{O}} J_{\mathrm{H}_{2} \mathrm{O}}+$ $\left(1-F_{\mathrm{H}_{2} \mathrm{O}}\right) J_{\mathrm{O}_{3}}$ where $F_{\mathrm{H}_{2} \mathrm{O}}$ is the relative fraction of $\mathrm{HO}_{\mathrm{x}}$ production that is due to the photolysis of water vapor. Fig-

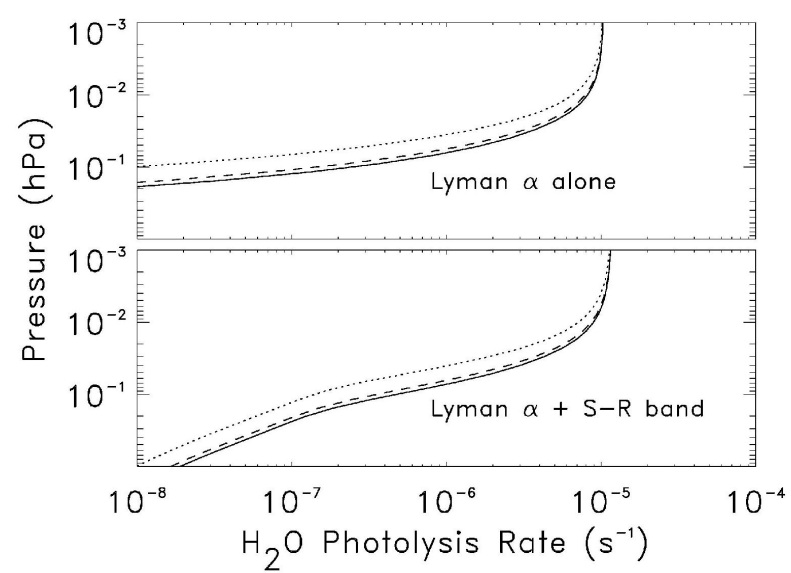

Fig. 6. Photodissociation rates for water vapor for Lyman $\alpha$ wavelengths (top) and for Lyman $\alpha$ plus the S-R band spectral region (bottom). In both plots, the solid, dashed, and dotted curves correspond to SZA values of $0^{\circ}, 30^{\circ}$ and $60^{\circ}$, respectively.

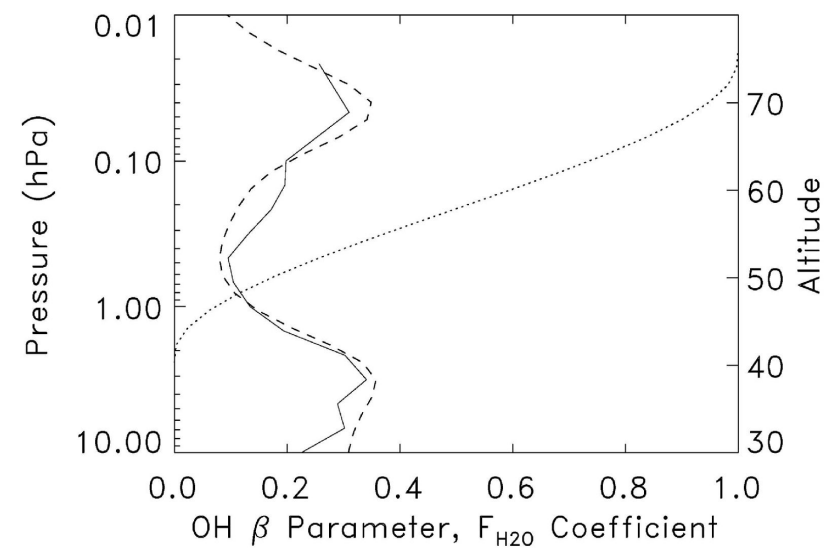

Fig. 7. Mean $\beta$ from 2004-2008 MLS OH measurements (solid), along with the best-fit $\beta$ profile using a linear combination of ozone and water vapor photodissociation raised to the power of 0.45 (dashed). The dotted curve shows the implied relative contribution of water vapor photodissociation to the total production of $\mathrm{HO}_{\mathrm{x}}\left(F_{\mathrm{H}_{2} \mathrm{O}}\right.$, as described in the text).

ure 7 demonstrates that the observed $\mathrm{OH} \beta$ profile is very well simulated by a simple linear combination of two photolysis rates, $J_{\mathrm{H}_{2} \mathrm{O}}$ and $J_{\mathrm{O}_{3}}$, and that the relative contribution of each photolysis process to $\mathrm{HO}_{\mathrm{x}}$ production is tightly constrained by the observations. Below about $1 \mathrm{hPa}(\sim 47 \mathrm{~km})$, the production of $\mathrm{HO}_{\mathrm{x}}$ occurs primarily through $J_{\mathrm{O}_{3}}$ and Reaction (R1), while above about $0.06 \mathrm{hPa}(\sim 67 \mathrm{~km}), \mathrm{HO}_{\mathrm{x}}$ production is mainly from $J_{\mathrm{H}_{2} \mathrm{O}}$ (Reaction R2). Both of these processes are important in the region between these two levels. 


\section{Conclusions}

Diurnal variations of $\mathrm{OH}$ in the stratosphere and mesosphere as observed by MLS are well described by exponential functions of the secant of SZA. This dependence is remarkably consistent from year to year between 2004 and 2008, provided that $\mathrm{H}_{2} \mathrm{O}$ and $\mathrm{O}_{3}$ are approximately constant and the SZA is restricted to angles less than $75^{\circ}$. The $\mathrm{OH}$ diurnal variation is fit to a function of the form $[\mathrm{OH}]=[\mathrm{OH}]_{\mathrm{o}} \exp [-\beta \sec (\mathrm{SZA})]$, where $[\mathrm{OH}]_{\mathrm{o}}$ and $\beta$ are altitude-dependent fit parameters. The vertical profile of $\beta$ is determined by the vertical profiles of photodissociation of water vapor and ozone, and by their relative contributions to the total production of $\mathrm{HO}_{\mathrm{x}}$.

For water vapor, diurnal variations in the photodissociation rate are controlled by the penetration of the solar flux in the Lyman $\alpha$ and S-R band spectral regions, with both of these effects governed by the molecular oxygen column abundance. A transition in water vapor photodissociation from Lyman $\alpha$ to S-R band spectral regions between 70 and $75 \mathrm{~km}$ altitude is clearly demonstrated by the observed $\mathrm{OH}$ variation with SZA.

For ozone, variations in the photodissociation rate with altitude and solar zenith angle are set primarily by the shape of the Hartley band ozone cross section and by the fact that atmospheric opacity is dominated by ozone absorption. This leads to a local maximum in the stratosphere for the mean optical depth relevant to ozone photolysis.

The overall shape of the $\beta$ profile can be used to quantify the relative importance of the photodissociation of ozone and water vapor to $\mathrm{HO}_{\mathrm{x}}$ production. Water vapor photolysis generally dominates above about $0.2 \mathrm{hPa}(\sim 60 \mathrm{~km})$, while ozone photolysis is most important below this level.

The characterization of $\mathrm{OH}$ diurnal variability presented here will be useful for future studies of hydroxyl and the use of MLS OH for testing our understanding of key photochemical processes in the stratosphere and mesosphere. In particular, the next phase of investigation will utilize these results to better define the relationship between $\mathrm{OH}$ and the $\mathrm{HO}_{\mathrm{x}}$ source gases $\mathrm{H}_{2} \mathrm{O}, \mathrm{O}_{3}$, and $\mathrm{CH}_{4}$.

Acknowledgements. This research was supported by NASA grant NNX08AN78G to NMT. Work at the Jet Propulsion Laboratory, California Institute of Technology was done under contract with the National Aeronautics and Space Administration. Herb Pickett's role as PI of the MLS OH measurements is acknowledged; the work presented here was made possible only through Herb's substantial accomplishments in instrument design and construction, retrieval algorithms, and data validation. We thank Martyn Chipperfield of Leeds University, UK, who developed the SLIMCAT model, for making the code available to us. The useful comments and suggestions of two anonymous referees is acknowledged.

Edited by: A. Baumgaertner

\section{References}

Allen, M., Lunine, J. I., and Yung, T. L.: The vertical distribution of ozone in the mesosphere and lower thermosphere, J. Geophys. Res., 89, 4841-4872, 1984.

Anderson, G. P., Clough, S. A., Kneizys, F. X., Chetwynd, J. H., and Shettle, E. P.: AFGL atmospheric constituent profiles (0-120km), AFGL Tech. Rep., AFGL-TR-86-0110, 43 pp., Air Force Phillips Lab., Hanscom AFB, Mass., 1986.

Brasseur, G. and Solomon, S.: Aeronomy of the Middle Atmosphere (3rd ed.), Springer, Dordrecht, 2005.

Burnett, C. R., Minschwaner, K., and Burnett, E. B.: Vertical column abundance measurements of atmospheric hydroxyl from $26^{\circ}, 40^{\circ}$ and $65^{\circ} \mathrm{N}$, J. Geophys. Res., 93, 5241-5253, 1989.

Canty, T. and Minschwaner, K.: Seasonal and solar cycle variability of $\mathrm{OH}$ in the middle atmosphere, J. Geophys. Res., 107, 4737, doi:10.1029/2002JD002278, 2002.

Canty, T., Pickett, H. M., Salawitch, R. J., Jucks, K. W., Traub, W. A., and Waters, J. W.: Stratospheric and mesospheric HOx: Results from Aura MLS and FIRS-2, Geophys. Res. Lett., 33, L12802, doi:10.1029/2006GL025964, 2006.

Chipperfield, M. P.: Multiannual simulations with a three dimensional chemical transport model, J. Geophys. Res., 104, 17811805, 1999.

Chipperfield, M. P.: New version of the TOMCAT/SLIMCAT offline chemical transport model: Intercomparison of stratospheric tracer experiments, Q. J. R. Meteorol. Soc., 132, 1179-1203, 2006.

Dvortsov, V. L. and Solomon, S.: Response of the stratospheric temperatures and ozone to past and future increases in stratospheric humidity, J. Geophys. Res., 106, 7505-7514, 2001.

Englert, C. R., Stevens, M. H., Siskind, D. E., Harlander, J. M., Roesler, F. L., Pickett, H. M., von Savigny, C., and Kochenash, A. J.: First results from the Spatial Heterodyne Imager for Mesospheric Radicals (SHIMMER): Diurnal variation of mesospheric hydroxyl, Geophys. Res. Lett., 35, L19813, doi:10.1029/2008GL035420, 2008.

Gattinger, R. I., Degenstein, D. A., and Llewellyn, E. J.: Optical spectrograph and infra-Red Imaging System (OSIRIS) observations of mesospheric $\mathrm{OH} \mathrm{A} \mathrm{A}^{2} \Sigma^{+}-X^{2} \Pi 0-0$ and 11 band resonance emissions, J. Geophys. Res., 111, D13303, doi:10.1029/2005JD006369, 2006.

Hanisco, T. F., Lanzendorf, E. J., Wennberg, P. O., Perkins, K. K., Stimpfle, R. M., Voss, P. B., Anderson, J. G., Cohen, R. C., Fahey, D. W., Gao, R. S., Hintsa, E. J., Salawitch, R. J., Margitan, J. J., McElroy, C. T., and Midwinter, C.: Sources, sinks, and the distribution of $\mathrm{OH}$ in the lower stratosphere, J. Phys. Chem. A, 105, 1543-1553, 2001.

Lewis, B. R., Vardavas, I. M., and Carver, J. H.: The aeronomic dissociation of water vapor by solar H Lyman a radiation, J. Geophys. Res., 88, 4935-4940, 1983.

Li, K-F., Cageao, R. P., Karpilovsky, E. P., Mills, F. P., Yung, Y. L., Margolis, J. S., and Sander, S. P.: OH column abundance over Table Mountain Facility, California: AM-PM diurnal asymmetry, Geophys. Res. Lett., 32, L13813, doi:10.1029/2005GL022521, 2005.

McElroy, M. B. and Salawitch, R. J.: Changing composition of the global stratosphere, Science, 243, 763-770, 1989.

Meier, R. R. and D. E. Anderson, Radiation field in the troposphere and stratosphere from 240-1000 nm - I: General analysis, Planet. 
Space Sci., 30, 923-933, 1982.

Mills, F. P., Cageao, R. P., Sander, S. P., Allen, M., Yung, Y. L., Remsberg, E. E., Russell, J. M., and Richter, U.: $\mathrm{OH}$ column abundance over Table Mountain Facility, California: Intra-annual variations and comparisons to model predictions for 1997-2001, J. Geophys. Res., 108(D24), 4785, doi:10.1029/2003JD003481, 2003.

Minschwaner, K., Salawitch, R. J., and McElroy, M. B.: Absorption of solar radiation by $\mathrm{O}_{2}$ : implications for $\mathrm{O}_{3}$ and lifetimes of $\mathrm{N}_{2} \mathrm{O}, \mathrm{CFCl}_{3}$, and $\mathrm{CF}_{2} \mathrm{Cl}_{2}$, J. Geophys. Res., 98, 10543-10561, 1993.

Nicolet, M.: On the photodissociation of water vapour in the mesosphere, Planet. Space Sci., 32, 871-880, 1984.

Pickett, H. M., Drouin, B. J., Canty, T., Salawitch, R. J., Fuller, R. A., Perun, V. S., Livesey, N. J., Waters, J. W., Stachnik, R. A., Sander, S. P., Traub, W. A., Jucks, K. W., and Minschwaner, K.: Validation of Aura Microwave Limb Sounder $\mathrm{OH}$ and $\mathrm{HO}_{2}$ measurements, J. Geophys. Res., 113, D16S30, doi:10.1029/2007JD008775, 2008.

Salawitch, R. J., Wofsy, S. C., Wennberg, P. O., Cohen, R. C., Anderson, J. G., Fahey, D. W., Gao, R. S., Keim, E. R., Woodbridge, E. L., Stimple, R. M., Koplow, J. P., Kohn, D. W., Webster, C. R., May, R. D., Pfister, L., Gottlieb, E. W., Michelson, H. A., Yue, G. K., Prather, M. J., WIlson, J. C., Brock, C. A., Jonsson, H. H., Dye, J. E., Baumgardner, D., Proffitt, M. H., Loewenstein, M., Podolske, J. R., Elkins, J. W., Dutton, G. S., Hintsa, E. J., Dessler, A. E., Weinstock, E. M., Kelly, K. K., Boering, K. A., Daube, B. C., Chan, K. R., and Bowen, S. W.: The diurnal variation of hydrogen, nitrogen, and chlorine radicals: implications for the heterogeneous production of $\mathrm{HNO}_{2}$, Geophys. Res. Lett., 21, 2551-2554, 1994.

Siskind, D. E., Minschwaner, K., and Eckman, R. S.: Photodissociation of $\mathrm{O}_{2}$ and $\mathrm{H}_{2} \mathrm{O}$ in the middle atmosphere: comparison of numerical methods and impact on model $\mathrm{O}_{3}$ and $\mathrm{OH}$, Geophys. Res. Lett., 21, 863-866 1994.
Wang, S. H., Pickett, H. M., Pongetti, T. J., Cheung, R., Yung, Y. L., Shim, C., Li, Q. B., Canty, T., Salawitch, R. J., Jucks, K. W., Drouin, B., and Sander, S. P.: Validation of Aura Microwave Limb Sounder $\mathrm{OH}$ measurements with Fourier transform ultraviolet spectrometer total $\mathrm{OH}$ column measurements at Table Mountain, California, J. Geophys. Res., 113, D22301, doi:10.1029/2008JD009883, 2008.

Waters, J. W., Froidevaux, L., Harwood, R. S., Jarnot, R. F., Pickett, H. M., Read, W. G., Siegel, P. H., Cofield, R. E., Filipiak, M. J., Flower, D. A., Holden, J. R., Lau, G. K. K., Livesey, N. J., Manney, G. L., Pumphrey, H. C., Santee, M. L., Wu, D. L., Cuddy, D. T., Lay, R. R., Loo, M. S., Perun, V. S., Schwartz, M. J., Stek, P. C., Thurstans, R. P., Boyles, M. A., Chandra, K. M., Chavez, M. C., Chen, G. S., Chudasama, B. V., Dodge, R., Fuller, R. A., Girard, M. A., Jiang, J. H., Jiang, Y. B., Knosp, B. W., LaBelle, R. C., Lam, J. C., Lee, K. A., Miller, D., Oswald, J. E., Patel, N. C., Pukala, D. M., Quintero, O., Scaff, D. M., Van Snyder, W., Tope, M. C., Wagner, P. A., and Walch, M. J.: The Earth Observing System Microwave Limb Sounder (EOS MLS) on the Aura satellite, IEEE T. Geosci. Remote, 44, 1075-1092, 2006.

Wennberg, P. O.: Radicals follow the sun, Nature, 442, 145-146, 2006.

Wennberg, P. O., Cohen, R. C., Stimple, R. M., Koplow, J. P., ANderson, J. G., Salawitch, R. J., Fahey, D. W., Woodbridge, E. L., Keim, E. R., Gao, R. S., Webster, C. R., May, R. D., Toohey, D. W., Avallone, L. M., Proffitt, M. H., Loewenstein, M., Podolske, J. R., Chan, K. R., and Wofsy, S. C.: Removal of stratospheric $\mathrm{O}_{3}$ by radicals: In situ measurements of $\mathrm{OH}, \mathrm{HO}_{2}, \mathrm{NO}, \mathrm{NO}_{2}$, ClO, and BrO, Science, 226, 398-404, 1994. 